NASA/TM-2001-210958

AIAA-2001-2252

Near Field Screech Noise Computation for an Underexpanded Supersonic Jet by the CE/SE Method

Ching Y. Loh

Taitech, Inc., Cleveland, Ohio

Lennart S. Hultgren and Philip C.E. Jorgenson

Glenn Research Center, Cleveland, Ohio 
Since its founding, NASA has been dedicated to the advancement of aeronautics and space science. The NASA Scientific and Technical Information (STI) Program Office plays a key part in helping NASA maintain this important role.

The NASA STI Program Office is operated by Langley Research Center, the Lead Center for NASA's scientific and technical information. The NASA STI Program Office provides access to the NASA STI Database, the largest collection of aeronautical and space science STI in the world. The Program Office is also NASA's institutional mechanism for disseminating the results of its research and development activities. These results are published by NASA in the NASA STI Report Series, which includes the following report types:

- TECHNICAL PUBLICATION. Reports of completed research or a major significant phase of research that present the results of NASA programs and include extensive data or theoretical analysis. Includes compilations of significant scientific and technical data and information deemed to be of continuing reference value. NASA's counterpart of peerreviewed formal professional papers but has less stringent limitations on manuscript length and extent of graphic presentations.

- TECHNICAL MEMORANDUM. Scientific and technical findings that are preliminary or of specialized interest, e.g., quick release reports, working papers, and bibliographies that contain minimal annotation. Does not contain extensive analysis.

- CONTRACTOR REPORT. Scientific and technical findings by NASA-sponsored contractors and grantees.
- CONFERENCE PUBLICATION. Collected papers from scientific and technical conferences, symposia, seminars, or other meetings sponsored or cosponsored by NASA.

- SPECIAL PUBLICATION. Scientific, technical, or historical information from NASA programs, projects, and missions, often concerned with subjects having substantial public interest.

- TECHNICAL TRANSLATION. Englishlanguage translations of foreign scientific and technical material pertinent to NASA's mission.

Specialized services that complement the STI Program Office's diverse offerings include creating custom thesauri, building customized data bases, organizing and publishing research results ... even providing videos.

For more information about the NASA STI Program Office, see the following:

- Access the NASA STI Program Home Page at http://www.sti.nasa.gov

- E-mail your question via the Internet to help@sti.nasa.gov

- Fax your question to the NASA Access Help Desk at 301-621-0134

- Telephone the NASA Access Help Desk at 301-621-0390

- Write to:

NASA Access Help Desk

NASA Center for AeroSpace Information 7121 Standard Drive Hanover, MD 21076 


\section{Near Field Screech Noise Computation for an Underexpanded Supersonic Jet by the CE/SE Method}

Ching Y. Loh

Taitech, Inc., Cleveland, Ohio

Lennart S. Hultgren and Philip C.E. Jorgenson

Glenn Research Center, Cleveland, Ohio

Prepared for the

Seventh Aeroacoustics Conference

cosponsored by the American Institute of Aeronautics and Astronautics and the Confederation of European Aerospace Societies

Maastricht, The Netherlands, May 28-30, 2001

National Aeronautics and Space Administration

Glenn Research Center 


\section{Acknowledgments}

The authors wish to thank Dr. J. Panda for fruitful discussions about the jet-screech phenomena, and for kindly providing his detailed experimental data. This work received support from the Supersonic

Propulsion Technology Project Office of NASA Glenn Research Center.

Available from

NASA Center for Aerospace Information 7121 Standard Drive

Hanover, MD 21076
National Technical Information Service 5285 Port Royal Road Springfield, VA 22100 


\title{
NEAR FIELD SCREECH NOISE COMPUTATION FOR AN UNDEREXPANDED SUPERSONIC JET BY THE CE/SE METHOD
}

\author{
Ching Y. Loh \\ Taitech, Inc. \\ Cleveland, Ohio 44135 \\ Lennart S. Hultgren and Philip C.E. Jorgenson \\ National Aeronautics and Space Administration \\ Glenn Research Center \\ Cleveland, Ohio 44135
}

\begin{abstract}
The space-time conservation element and solution element (CE/SE) method is employed to numerically study the near-field axisymmetric screech-tone noise of a typical underexpanded circular jet issuing from a sonic nozzle. For the computed cases, corresponding to fully expanded Mach numbers of 1.10, 1.15 and 1.19, the self-sustained feedback loop is automatically established. The computed shock-cell structure, acoustic wave length, screech tone frequencies, and sound pressure levels are in good agreement with experimental results.
\end{abstract}

\section{Introduction}

An underexpanded supersonic jet radiates mixing noise, broadband shock-associated noise, as well as screech tones under certain conditions. These complicated and technologically important physical phenomena have been the topic of many experimental and theoretical investigations, see the review papers [1-4] for a comprehensive list of references and discussion. Simply put, the mixing noise is directly associated with large-scale structures, or instability waves. in the jet shear layer; whereas, the broadband shock-associated noise and screech tones are associated with the interaction of these waves with the shock-cell structure in the jet core. The screech tones arise due to a feedback loop, i.e., part of the acoustic waves generated by the wave/shock-cell interaction propagate upstream and re-generate the instability waves at, or in the vicinity of, the nozzle lip. Screech tones are of particular interest not only because of general noisereduction concerns, but also because of potentially destructive structural interaction(s) leading to sonic fatigue. The feedhack loop leading to screech tones is sensitive to small changes in the system conditions, and the understanding of the phenomena is to date mostly based on experimental observations [5-9].
Reliable direct numerical simulation of jet screech noise has up to quite recently not been feasible. The numerical scheme is required, on one hand, to resolve the acoustic waves without too much dispersion error and numerical dissipation, while on the other hand, it is required to capture shocks, or other nonlinear phenomena, near or inside the jet correctly. In addition, nonreflecting boundary conditions must be implemented, which is more difficult to accomplish in the near field than in the far field.

Shen and Tam $[10,11]$ obtained excellent results in a direct numerical simulation of screech for circular jets, using the well-known DRP scheme. A medium size computational domain of $35 \mathrm{D}$ long in the streamwise direction and $17 D$ in radial direction is employed in their computation, where $D$ is the nozzle diameter.

The space-time conservation element and solution element method (CE/SE) [12-15] is another scheme that meets the above requirements. As demonstrated in our previous papers, the CE/SE scheme is well suited for computing waves on compressible shear flows [16] as well as vorticity/shock interactions [17], both being cornerstones of the jet-noise phenomena. Because of the CE/SE non-reflecting boundary conditions (NRBC), which are based on flux balance, a much smaller near field computational domain $(12 D \times 8 D)$ can be used in the present numerical simulation.

The unstructured-grid axisymmetric CE/SE scheme used here is briefly discussed in Section 2. Section 3 illustrates the initial and boundary conditions for the screech problem, in particular, the CE/SE NRBC. The numerical results are presented and compared to available experimental findings [5-9] in Section 4. Conclusions are drawn in Section 5.

\section{The Unstructured Axisymmetric CE/SE Navier-Stokes Solver}

In this Section. several new developments of the $\mathrm{CE} / \mathrm{SE}$ numerical method are applied: (a) use of an 
unstructured grid, which helps to facilitate the numerical implementation [15]; (b) the Navier-Stokes CE/SE solver; and (c) the axisymmetric LES (large eddy simulation), which accounts for the strong momentum exchange between the jet and the ambient flow and results in a much improved numerical simulation. These new developments are described in the following subsections.

\subsection{Conservation Form of the Unsteady Axisymmetric Navier-Stokes Equations}

In general, the CE/SE method systematically solves a set of integral equations derived directly from the physical conservation laws and naturally captures shocks and other discontinuities in the flow. Both dependent variables and their derivatives are computed simultaneously. As a consequence, the flow vorticity can be obtained without reduction in accuracy. Non-reflecting boundary conditions (NRBCs) are also easily implemented because of the flux-conservation formulation.

Consider a dimensionless conservation form of the unsteady axisymmetric Navier-Stokes equations of a perfect gas. Let $\rho, u, v, p$, and $\gamma$ be the density, streamwise velocity component, radial velocity component, static pressure, and constant specific heat ratio, respectively. The axisymmetric Navier-Stokes equations then can be written in the following vector form:

$$
U_{t}+F_{x}+G_{y}=Q
$$

where $x, y \geqslant 0$, and $t$ are the streamwise and radial coordinates and time, respectively. The conservative flow variable vector $U$ and the flux vectors in the streamwise and radial directions, $\boldsymbol{F}$ and $\boldsymbol{G}$, are given by:

$$
\boldsymbol{U}=\left(\begin{array}{c}
U_{1} \\
U_{2} \\
U_{3} \\
U_{4}
\end{array}\right), \quad \boldsymbol{F}=\left(\begin{array}{c}
F_{1} \\
F_{2} \\
F_{3} \\
F_{4}
\end{array}\right), \quad \boldsymbol{G}=\left(\begin{array}{c}
G_{1} \\
G_{2} \\
G_{3} \\
G_{4}
\end{array}\right),
$$

with

$$
\begin{gathered}
U_{1}=\rho, \quad U_{2}=\rho u, \quad U_{3}=\rho v \\
U_{4}=p /(\gamma-1)+\rho\left(u^{2}+v^{2}\right) / 2 .
\end{gathered}
$$

The flux vectors are further split into inviscid and viscous fluxes:

$$
\mathbf{F}=\mathbf{F}_{\mathbf{i}}-\mathbf{F}_{\mathbf{v}}, \mathbf{G}=\mathbf{G}_{\mathbf{i}}-\mathbf{G}_{\mathbf{v}}
$$

where the inviscid fluxes are the same as in the Euler equations:

$$
\begin{gathered}
F_{i 1}=U_{2} \\
F_{i 2}=(\gamma-1) U_{4}+\left[(3-\gamma) U_{2}^{2}-(\gamma-1) U_{3}^{2}\right] / 2 U_{1}, \\
F_{i 3}=U_{2} U_{3} / U_{1}, \\
F_{i 4}=\gamma U_{2} U_{4} / U_{1}-(\gamma-1) U_{2}\left[U_{2}^{2}+U_{3}^{2}\right] / 2 U_{1}^{2}, \\
G_{i 1}=U_{3}, \quad G_{i 2}=U_{2} U_{3} / U_{1}
\end{gathered}
$$

$$
\begin{gathered}
G_{i 3}=(\gamma-1) U_{4}+\left[(3-\gamma) U_{3}^{2}-(\gamma-1) U_{2}^{2}\right] / 2 U_{1} \\
G_{i 4}=\gamma U_{3} U_{4} / U_{1}-(\gamma-1) U_{3}\left[U_{2}^{2}+U_{3}^{2}\right] / 2 U_{1}^{2}
\end{gathered}
$$

and the viscous fluxes are:

$$
\begin{gathered}
F_{v 1}=0, \quad F_{v 2}=\mu\left(2 u_{x}-\frac{2}{3} \nabla \cdot \mathbf{V}\right), \\
F_{v 3}=\mu\left(v_{x}+u_{y}\right), \\
F_{v 4}=\mu\left[2 u u_{x}+\left(u_{y}+v_{x}\right) v-\frac{2}{3}(\nabla \cdot \mathbf{V}) u+\right. \\
\left.\frac{\gamma}{\operatorname{Pr}} \frac{\partial}{\partial y}\left(\frac{U_{4}}{U_{1}}-\frac{u^{2}+v^{2}}{2}\right)\right], \\
G_{v 1}=0, \quad G_{v 2}=\mu\left(v_{x}+u_{y}\right), \\
G_{v 33}=\mu\left(2 v_{y}-\frac{2}{3} \nabla \cdot \mathbf{V}\right), \\
G_{v 4}=\mu\left[2 v v_{y}+\left(u_{y}+v_{x}\right) u-\frac{2}{3}(\nabla \cdot \mathbf{V}) v+\right. \\
\left.\frac{\gamma}{\operatorname{Pr}} \frac{\partial}{\partial y}\left(\frac{U_{4}}{U_{1}}-\frac{u^{2}+v^{2}}{2}\right)\right],
\end{gathered}
$$

where $u, v, u_{x}, u_{y}, v_{x}, v_{y}$ are respectively the $x$ - and $y-$ flow velocity components and their derivatives, which can be written in terms of the conservative variables $U_{1}, U_{2}, U_{3}$ and $U_{4}$, with $\operatorname{Pr}(=0.72)$ being the Prandtl number, $\mu$ the viscosity, the velocity divergence

$$
\nabla \cdot \mathbf{V}=u_{x}+v_{y}+v / y
$$

The right hand source term $Q$ is the same as in the axisymmetric Euler equations [18]:

$$
\boldsymbol{Q}=\left(\begin{array}{l}
Q_{1} \\
Q_{2} \\
Q_{3} \\
Q_{4}
\end{array}\right)
$$

where

$$
\begin{gathered}
Q_{1}=-U_{3} / y, \quad Q_{2}=-U_{2} U_{3} / U_{1} y \\
Q_{3}=-U_{3}^{2} / U_{1} y, \quad Q_{4}=-G_{4} / y .
\end{gathered}
$$

By considering $(x, y, t)$ as coordinates of a threedimensional Euclidean space, $E_{3}$, and using Gauss' divergence theorem, it follows that Eq. (1) is equivalent to the following integral conservation law:

$$
\oint_{S(V)} \boldsymbol{H}_{m} \cdot \mathrm{d} \mathbf{S}=\int_{V} Q_{m} \mathrm{~d} V, \quad m=1,2,3,4, \quad \text { (2) }
$$

where $S(V)$ denotes the surface around a volume $V$ in $E_{3}$ and $\boldsymbol{H}_{m}=\left(F_{m}, G_{m}, U_{m}\right)$. 

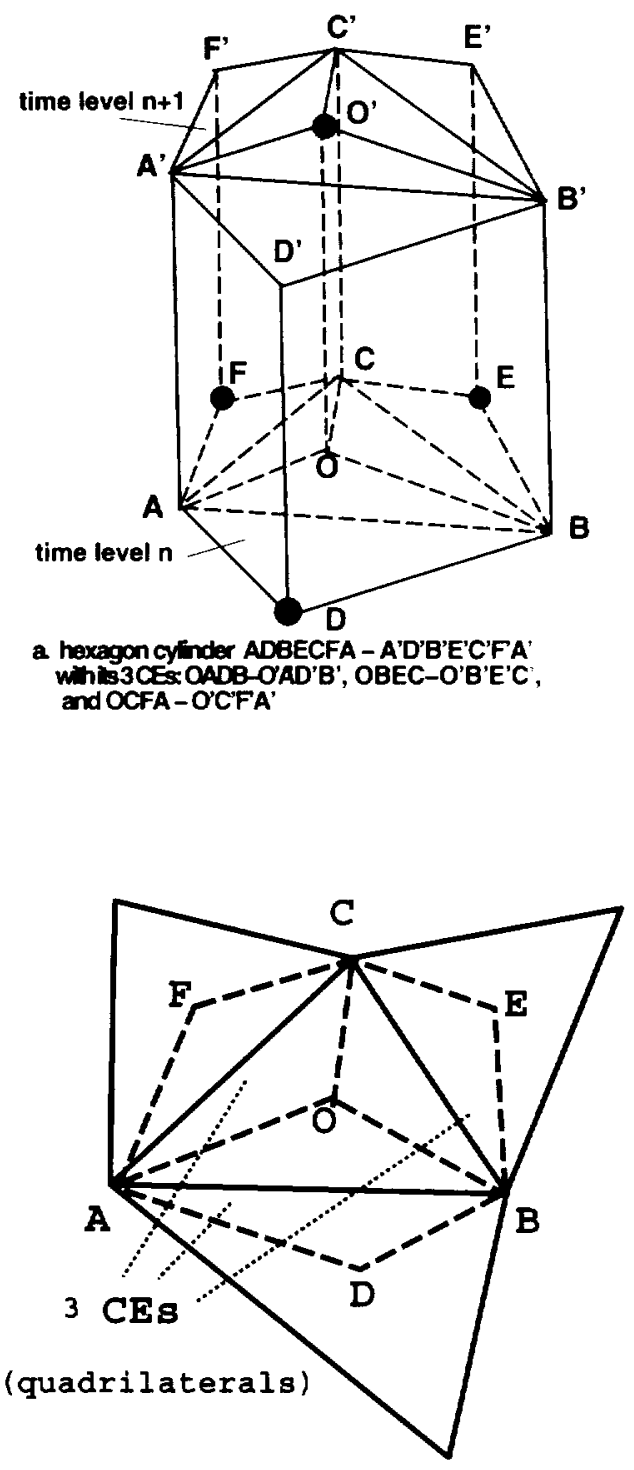

b. projection of $E_{3}$ in the $x-y$ plane

Figure 1: $\mathrm{CE} / \mathrm{SE}$ unstructured grid

\subsection{Unstructured Grid for CE/SE}

The CE/SE scheme is constructed to take advantage of an unstructured triangle grid. The unstructured geometry used with the CE/SE scheme is illustrated in Fig. 1. Here, $\triangle A B C$ is a typical triangle cell and $D, E, F$ are the triangle centers of the neighboring cells. The flow variables at the previous time step are stored at the triangle cell centers. Three quadrilateral cylinders (conservation elements) are formed by the edges that connect the vertices and the center of the triangle and its three neighbors. The projection of these cylinders in the $x-y$ plane are shown in Fig. 1(b) and the $C E$ 's are shown in Fig. I(a). In the space-time $E_{3}$ space, Eq. (2) is applied to the hexagon cylinder (of volume $V$ ) that consists of these 3 quadrilateral cylinder $C E \mathrm{~s}$, see Fig 1(a). The discrete approximation of $\mathrm{Eq}$. (2) is then

$$
\oint_{S(1)} \boldsymbol{H}_{m}^{*} \cdot \mathrm{d} \mathbf{S}=V\left(Q_{m}\right)_{j}^{n+1},
$$

for $m=1,2,3,4$, where $\boldsymbol{H}_{m}^{*}=\left(F_{m}^{*}, G_{m}^{*}, U_{m}^{*}\right)$. The right-hand side of Eq. (3), in general, is the volume $V$ times the source term evaluated at an appropriate Gaussian quadrature node. Here, the Gaussian quadrature node is the center of the hexagon $A^{\prime} D^{\prime} B^{\prime} E^{\prime} C^{\prime} F^{\prime}$ at the time level $n+1$, i.e., $O^{\prime}$.

In the CE/SE scheme, the above flux conservation relation. Eq. (3), in space-time is the only mechanism that transfers information between node points. A conservation element $C E$ (here, quadrilateral cylinders) is the finite volume to which Eq. (3) is applied. Discontinuities are allowed to occur in a conservation element. A solution element $S E$ associated with a grid node (e.g., $D$, $E$, or $F$ in Fig. 1) is here a set of interface planes in $E_{3}$ that passes through this node (e.g. $D A A^{\prime} D^{\prime}, D B B^{\prime} D^{\prime}$, $E B B^{\prime} E^{\prime}, E C C^{\prime} E^{\prime}$, etc.). Each surface $S(C E)$ is made up of segments belonging to two neighboring $C E$ 's. Within a given solution element $S E(j, n)$, where $j, n$ are the node index and time step, respectively, the flow variables are not only considered continuous but are also approximated by the linear Taylor series expansions:

$$
\begin{gathered}
\boldsymbol{U}^{*}(x, y, t: j, n)=\boldsymbol{U}_{j}^{n}+\left(\boldsymbol{U}_{x}\right)_{j}^{n}\left(x-x_{j}\right)+ \\
\left(\boldsymbol{U}_{y}\right)_{j}^{n}\left(y-y_{j}\right)+\left(\boldsymbol{U}_{t}\right)_{j}^{n}\left(t-t^{n}\right), \\
\boldsymbol{F}^{*}(x, y, t ; j, n)=\boldsymbol{F}_{j}^{n}+\left(\boldsymbol{F}_{x}\right)_{j}^{n}\left(r-x_{j}\right)+ \\
\left(\boldsymbol{F}_{y}\right)_{j}^{n}\left(y-y_{j}\right)+\left(\boldsymbol{F}_{t}\right)_{j}^{n}\left(t-t^{n}\right) . \\
\boldsymbol{G}^{*}(x, y, t: j, n)=\boldsymbol{G}_{j}^{n}+\left(\boldsymbol{G}_{x}\right)_{j}^{n}\left(x-x_{j}\right)+ \\
\left(\boldsymbol{G}_{y}\right)_{j}^{n}\left(y-y_{j}\right)+\left(\boldsymbol{G}_{t}\right)_{j}^{n}\left(t-t^{n}\right) .
\end{gathered}
$$

where $j$ is the node index of $D, E$ or $F$. The partial derivatives of $\boldsymbol{F}$ and $\boldsymbol{G}$ can be related to the corresponding one of $U$ by using the chain rule with $U_{t}$ provided by Eq. (1). The surface flux can be calculated accurately 
and easily by first evaluating the flux vectors at the geometrical center of the surface through the above Taylor series expansions.

At time level $n$, the solution variables $U, U_{x}$, and $U_{y}$ are given at the three nodes $D, E, F$ in Fig. 1 and $\boldsymbol{U}, \boldsymbol{U}_{x}$ and $\boldsymbol{U}_{y}$ at $O^{\prime}$ at the new time level $n+1$ are to be computed. In principle, each of the $3 C E$ s provides 4 scalar equations when Eq. (3) is applied to the element. Hence, the 12 scalar equations needed for the 12 scalar unknowns at $O^{\prime}$ are available. All the unknowns are computed based on these relations. No extrapolations (interpolations) across a stencil of cells are needed. In practice, however, the dependent variables are first obtained at the hexagon center at the new time level $n+1$ using Eq. (3) and then their values at the center $O^{\prime}$ of the triangle $A B C$ can be obtained by a linear Taylor series expansion. Details can be found in [15].

With an unstructured grid, the CE/SE procedure is simplified and more easily adapted to complicated geometries. Only a single mesh is needed as compared to the spatially staggered mesh used in the structuredgrid case and the time-marching is completed in one step rather than two. Furthermore, the simple non-reflecting boundary conditions described previously [16-19] still work well with an unstructured grid. More details about the unstructured CE/SE method can be found in [15]. The weighted $a-\epsilon \mathrm{CE} / \mathrm{SE}$ scheme is used here.

\subsection{Treatment of the Source Term}

The treatment is identical to the one used in [18] and is briefly reiterated here. Since the source term $Q$ itself is a function of the unknown $U$, a local iterative procedure is needed to determine $U$. The discretized integral equation (3) reduces to the form

$$
\boldsymbol{U}-\boldsymbol{Q}(U) \Delta t=\boldsymbol{U}_{H},
$$

where $U_{H}$ is the local homogeneous solution $(Q=0$ locally). Note that $U_{H}$ only depends on the solution at the previous time step, i.e., $U_{H}$ is obtained using explicit formulas. A Newton iterative procedure to determine $U$ is then

$$
\boldsymbol{U}^{(i+1)}=\boldsymbol{U}^{(i)}-\left(\frac{\partial \boldsymbol{\Phi}}{\partial \boldsymbol{U}}\right)^{-1}\left[\boldsymbol{\Phi}\left(\boldsymbol{U}^{(i)}\right)-\boldsymbol{U}_{H}\right],
$$

where $i$ is the iteration number and

$$
\boldsymbol{\Phi}(\boldsymbol{U})=\boldsymbol{U}-\boldsymbol{Q}(\boldsymbol{U}) \Delta t .
$$

Normally, $U$ at the previous time step is a good initial guess $U^{(0)}$ and the procedure takes about 2-3 iterations to converge. The Jacobian matrix is given by

$$
\frac{\partial \Phi}{\partial \boldsymbol{U}}=\left(\begin{array}{cccc}
1 & 0 & \frac{\Delta t}{y} & 0 \\
-\frac{U_{2} U_{3} \Delta t}{U_{1}^{2} y} & 1+\frac{U_{3} \Delta t}{U_{1} y} & \frac{U_{2} \Delta t}{U_{1} y} & 0 \\
-\frac{U_{3}^{2} \Delta t}{U_{1}^{2} y} & 0 & 1+\frac{U_{3} \Delta t}{U_{1} y} & 0 \\
A_{1} & A_{2} & A_{3} & 1+\frac{\gamma I_{3} \Delta t}{2 I_{1} y}
\end{array}\right)
$$

where

$$
\begin{gathered}
A_{1}=-\frac{U_{3} \Delta t}{U_{1} y}\left[\gamma U_{4}-\frac{(\gamma-1)\left(U_{2}^{2}+U_{3}^{2}\right)}{U_{1}}\right] \\
A_{2}=-(\gamma-1) \frac{U_{2} U_{3} \Delta t}{U_{1}^{2} y} \\
A_{3}=\frac{\Delta t}{y}\left[-\frac{\gamma-1}{2} \frac{U_{2}^{2}+3 U_{3}^{2}}{U_{1}^{2}}+\frac{\gamma U_{4}}{U_{1}}\right]
\end{gathered}
$$

The inverse of the Jacobian, i.e., $\left(\frac{\partial \Phi}{\partial U}\right)^{-1}$ can easily be derived analytically for this particular case, thus, leading to a savings in CPU time.

\subsection{Large Eddy Simulation (LES)}

A simplified LES procedure similar to those used in [20] is adopted here to account for the strong momentum exchange in the shear layer. In the LES, a simple Smagorinsky subgrid scale model is used for the eddy viscosity:

$$
\mu_{t}=\left(C_{s} \Delta\right)^{2}\left(2 S_{i j} S_{i j}\right)^{1 / 2}
$$

where

$$
S_{i j}=\frac{1}{2}\left(\frac{\partial u_{i}}{\partial x_{j}}+\frac{\partial u_{j}}{\partial x_{i}}\right),
$$

with $\Delta=(\Delta x \Delta y)^{1 / 2}$ and $C_{s}=0.1$. Then, $\mu+\mu_{t}$ replaces $\mu$ in the actual computation. In practice, the LES model was only applied for radii less than $1.5 D$ and $4 D$ downstream of the nozzle exit plane.

\section{The Jet Screech Noise Problem}

Consider a circular jet as sketched in Fig. 2. The flow at the start of the computations is choked, i.e., nozzle exit Mach number, $M_{e}$, is unity, and the surrounding fluid is stationary. Three cases, which if fully expanded would have jet Mach numbers, $M_{j}$, of $1.10,1.15$, and 1.19, are considered. These conditions correspond to the experimental conditions of Panda [5-8]. In these experiments, it was shown that for $M_{j} \leqslant 1.19$, the jet noise field is in an axisymmetric mode. Hence, the axisymmetric CE/SE code described above is appropriate for computation at these conditions.

In the investigation, our attention is focussed on the near field of the nozzle since this is the noise source region. The diameter, $D$, of the jet nozzle is chosen as the length scale. The density, $\rho_{0}$, speed of sound, $a_{0}$, and temperature $T_{0}$ in the ambient flow are taken as scales for the dependent variables.

In order to clearly display the upstream propagating screech waves, the computational domain was extended $4 D$ upstream of the nozzle exit. The full computational domain is a circular cylinder of $12 \mathrm{D}$ axial length and $8 D$ radius. At the nozzle exit, the inflow plane is recessed by two cells so as not to numerically restrict or influence the feed-back loop. Ponton et. al.'s [9] straight nozzle lip of 


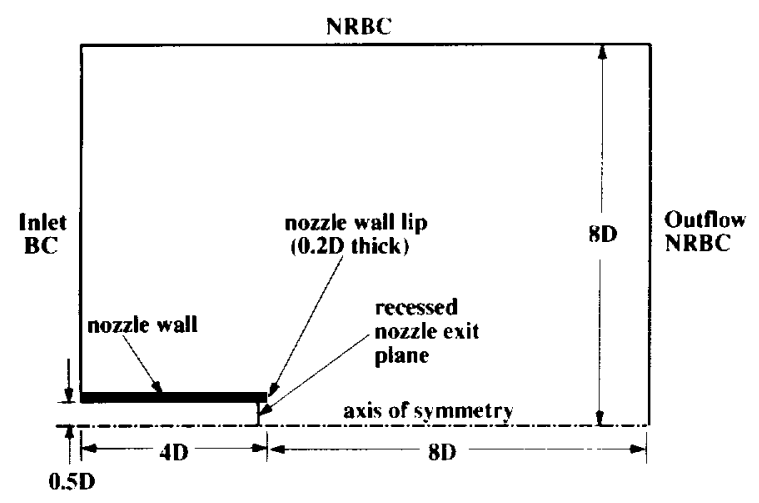

Figure 2: Geometry of the computational domain

$0.2 D$ in thickness is adopted in the CE/SE computations. Note that in the experimental setup of Panda [5,6], although the actual nozzle diameter is the same $(25.4 \mathrm{~mm})$ as in [9], the nozzle exit lip is $0.25 D$ thick and beveled.

The unstructured grid currently used is formed by cutting a rectangle cell into 4 triangles. These rectangular cells are non-uniform since good grid resolution is needed in the jet shear layer and their numbers in the $x$ and $y$ directions are typically 240 and 130 , respectively, corresponding to about 132000 triangles. The last 10 cells in the streamwise and radial directions have exponentially growing $x$ and $y$ size, respectively. and serve as buffer zones to essentially eliminate any small remaining numerical reflection from the outflow houndary. The CE/SE scheme is of the $a-\epsilon$ type $[1,3,14]$ with a weighting parameter $\alpha=0$ and $\epsilon=0.5$.

\subsection{Initial Conditions}

Initially, the flow of the entire domain is set at the ambient flow conditions, i.e., (using nondimensional variables)

$$
\rho_{0}=1, \quad p_{0}=\frac{1}{\gamma}, \quad u_{0}=0, \quad r_{0}=0 .
$$

\subsection{Boundary Conditions}

At the inlet boundary, the conservative flow variables and their spatial derivatives are specified to be those of the ambient flow, except at the nozzle exit, where an elevated pressure is imposed, i.e., the jet is under-expanded, as in the physical experiments. By using the ideal gas isentropic relations, it follows that the nondimensional flow variables at the nozzle exit, with $M_{\ell^{\prime}}=1$, are given by

$$
\begin{gathered}
\rho_{\mathrm{r}}=\frac{\gamma(\gamma+1) p_{c}}{2 T_{r}}, \\
p_{e}=\frac{1}{\gamma}\left[\frac{2+(\gamma-1) M_{j}^{2}}{\gamma_{i}+1}\right]^{\frac{\gamma}{\gamma}} .
\end{gathered}
$$

$$
u_{e}=\left(\frac{2 T_{r}}{\gamma+1}\right)^{1 / 2}, \quad v_{e}=0,
$$

where $T_{r}$ is the reservoir (plenum) temperature. We will also follow the experimental cold-flow condition where the reservoir temperature equals the ambient one, i.e., $T_{r}=1$.

At the symmetry axis, i.e., $y=0$, a simple reflective boundary condition is applied. At the top and outflow boundaries, the Type I and Type II CE/SE non-reflecting boundary conditions as described in the next subsection are imposed, respectively. The no-slip boundary condition is applied on the nozzle walls.

\subsection{Non-Reflecting Boundary Conditions}

In the CE/SE scheme, non-reflecting boundary conditions (NRBC) are constructed so as to allow fluxes from the interior domain of a boundary $C E$ to smoothly exit from the domain. There are various implementations of the non-reflecting boundary condition and in general they have proven to be well suited for aeroacoustic problems $[18,19]$. The following NRBCs are employed in this paper.

For a grid node $(j, n)$ lying at the outer radius of the domain the non-reflective boundary condition (Type I) requires that

$$
\left(\boldsymbol{U}_{x}\right)_{j}^{n}=\left(\boldsymbol{U}_{y}\right)_{j}^{n}=0
$$

while $U_{j}^{n}$ is kept fixed at the initial steady boundary value. At the downstream boundary, where there are substantial gradients in the radial direction, the nonreflective boundary condition (Type II) requires that

$$
\left(\boldsymbol{U}_{x}\right)_{j}^{n}=0
$$

while $U_{j}^{n}$ and $\left(U_{y}\right)_{j}^{n}$ are now defined by simple extrapolation from the nearest interior node $j^{\prime}$, i.e.,

$$
\boldsymbol{U}_{j}^{n}=\boldsymbol{U}_{j^{\prime}}^{n-1 / 2} \quad\left(\boldsymbol{U}_{y}\right)_{j}^{n}=\left(\boldsymbol{U}_{y}\right)_{j^{\prime}}^{n-1 / 2} .
$$

As will be observed later, these NRBCs, when combined with the above buffer zones, are robust enough to allow a near field computation without disturbing or distorting the flow and acoustic fields.

\section{Numerical Results}

In this section, numerical results for the axisymmetric underexpanded circular jet are presented and compared to experimental results [5-9]. Computations are conducted for three different jet Mach numbers $M_{j}=1.1$. 1.15 , and 1.19 . With an appropriate time step size, a large number (minimum 410,000) of time steps are run for these cases in order to achieve appropriate accuracy in the Fourier analysis of the time series data. 
It is important to emphasize that no harmonic forcing is imposed in the numerical simulation. The initial impact of the boundary condition at the nozzle exit stimulates the jet shear layer and triggers the feedback loop that generates the screech waves.

In the following, the computed jet flow data and acoustic screech data are presented separately, and comparisons are made with available experimental results.

\subsection{Time-Averaged Flow and Shock-Cell Structure}

For the typical case of $M_{j}=1.19$, Fig. 3 shows $p, \rho$, $u$ contours and a numerical Schlieren picture. They are time averaged over 40,000 time steps and are obtained after the start-up transients have moved out of the computational domain. In the $p, \rho$, and $u$ contours, the shock cell structure and the shear layer spreading are clearly captured. Note that although the LES model is highly simplified, it still distinctly affects the flow field. Since the momentum exchange around the shear layer is accounted for through a high local value of the eddy viscosity, the shear layer spreads much more rapidly as compared to our earlier related Euler computations [18], and the static pressure maximum increases by $15-20 \%$.

Experimental results for jets are often documented in terms of Schlieren pictures. It is straightforward to construct Schlieren graphs (density-gradient modulus) from the numerical results. Such a numerical plot is shown in the last panel of Fig. 3. A comparison of the numerical Schlieren contours from the current computations and the experimental Schlieren photograph in [5] (Fig. 4) shows good agreement in shock-cell structure. For example, the shock cell width is about $0.8 D$ in the streamwise direction. In both plots, it is observed that the first two shock cells appear to be sharp and clear since the shearlayer instability wave is too weak at these locations to significantly affect the shock cell. However, it interacts strongly with the shock cells once it has gained a sufficient amplitude through its streamwise growth, which is evident by the deformation of the third and fourth shock cells. The deformation and movement of the shock cells are also seen in the experiments $[5,6]$. This is, as pointed out by Seiner [2], the mechanism by which the acoustic waves that produce the broadband shock-associated noise and the screech tones are generated. Furthermore, the fifth shock cell and those further downstream are so severely deformed that they almost disappear.

\subsection{Near-Field Radiating Screech Waves}

For the same case of $M_{j}=1.19$, Fig. 5 illustrates the radiating screech waves at the time level of 410,000 steps. Since no forcing is applied in the numerical simulation, these waves are a clear indicator of a self-sustained oscillation. For this figure, the very high isohar level contours, corresponding to hydrodynamic waves around the p $(.363-.608)$
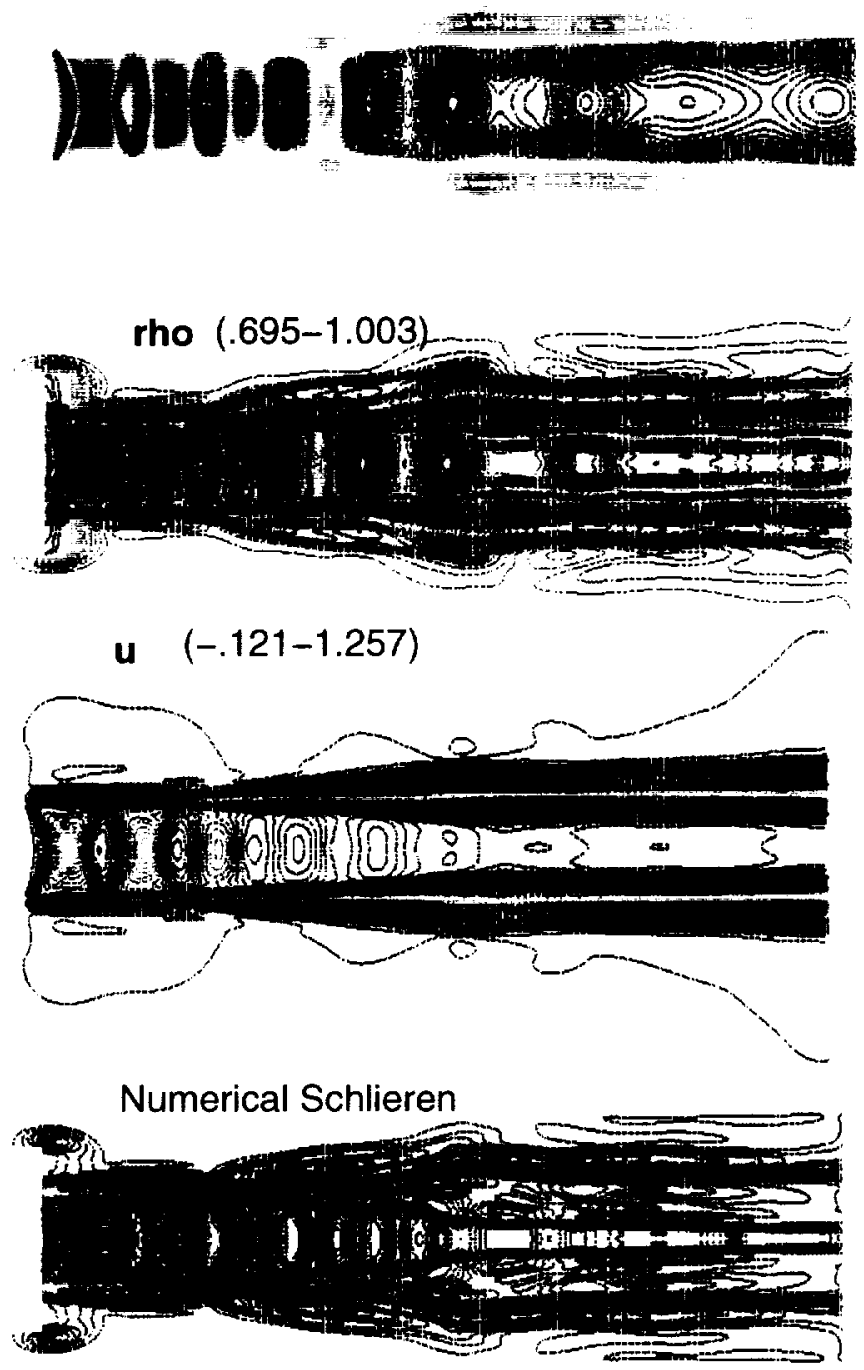

Figure 3: Time averaged $p, \rho$ and $u$ contours and numerical Schlieren plot, $M_{j}=1.19$.

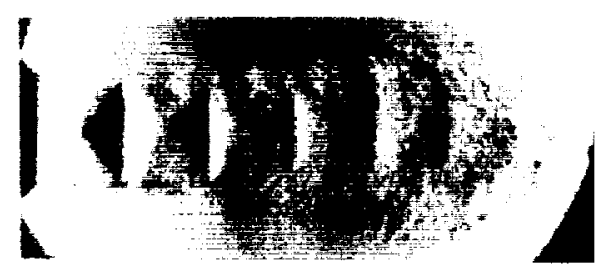

Figure 4: Experimental Schlieren plot showing shock cell structure, $M_{j}=1.19$. 


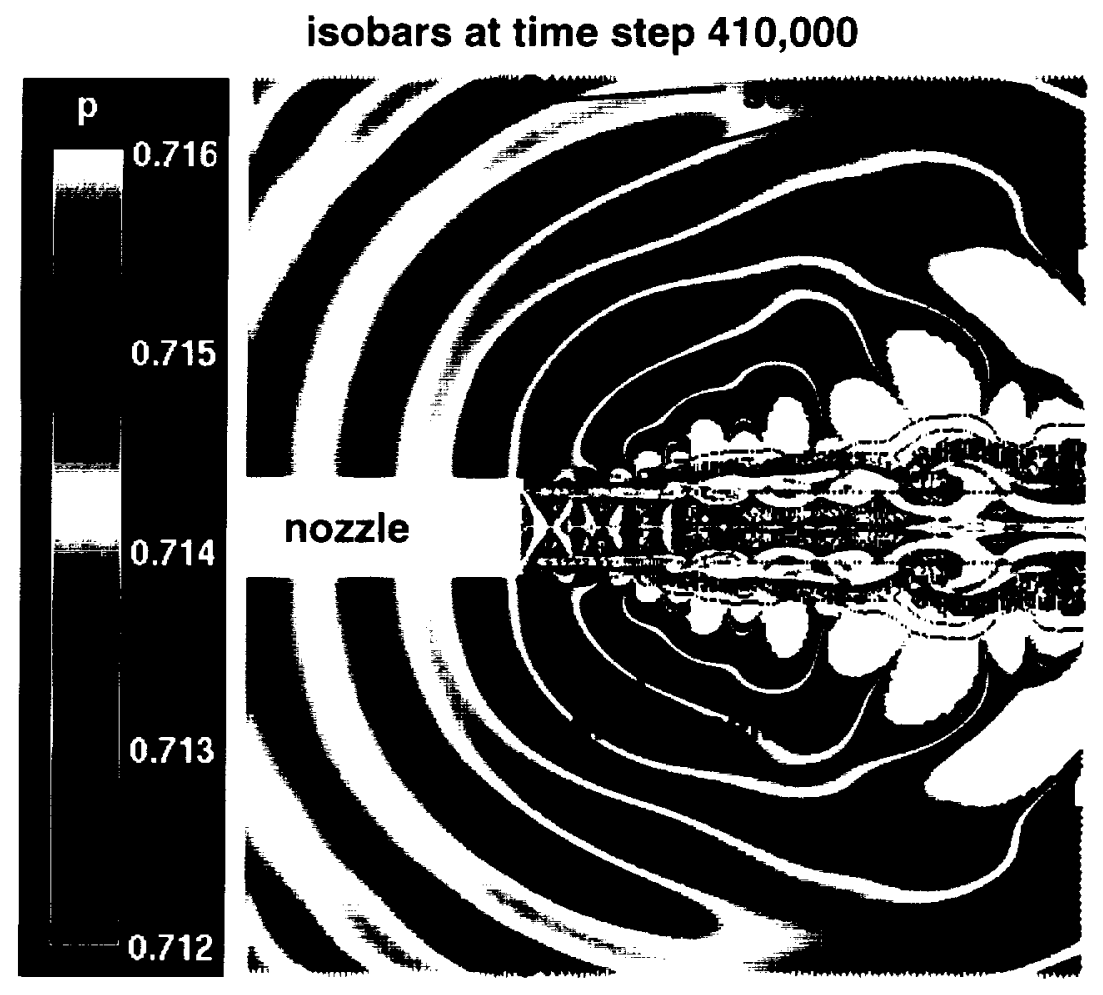

Figure 5: Screech wave radiation, $M_{j}=1.19$.

jet core area are 'cut off' and the 'colors' are appropriately adjusted so that the acoustic waves outside of the jet core are clearly displayed. Furthermore, the corresponding instantaneous numerical Schlieren image is superimposed on the plot in the core region. The screech wavelength is about $1.6 \mathrm{D}$, well in line with experimental results (e.g. [5]) and theoretical predictions. e.g. Seiner [2], Tam [1].

\subsection{Sound Pressure Level and Screech Frequency}

The numerical time history is recorded for a select number of locations in the flow field and later post-processed to obtain spectral information using Fast Fourier Transform (FFT) techniques. The data at a selected position is recorded every twentieth actual time step, and the recording begins after an initial time period has elapsed $(80,000$ actual time steps). Typically, each time trace contains 33,000 points and corresponds to more than 0.7 million computational time steps. Figure 6 is a time trace of the unsteady pressure at a location on the nozzle exit lip wall ( $x=4.0, y=0.642$ ) for $M_{j}=1.19$. The time signal is quite irregular.

Estimates of the sound pressure level (SPL), in $\mathrm{dB}$ are shown in Figs. 7-9. The abscissas denote frequency in $\mathrm{Hz}$. In the following, all the spectral analyses are conducted at the nozzle exit lip wall $(x=4.0, y=0 .(142)$.
This is the location used by Ponton et al [9] in their measurement, which is somewhat different from the location used by Panda [5].

Figure 7 displays the SPL for the case of $M_{j}=1.19$. The SPL shows that there are multiple spikes in the spectrum. The two distinct higher spikes correspond to screech frequencies of $8890 \mathrm{~Hz}$ (SPL $=126 \mathrm{~dB}, A_{2}$ mode) and $6945 \mathrm{~Hz}$ ( $\mathrm{SPL}=131 \mathrm{~dB}, A_{1}$ mode) respectively.

Figure 8 shows the SPL for the case of $M_{3}=1.15$. Still, there are multiple spikes in the spectrum. The two distinct higher spikes correspond to screech frequencies of $9410 \mathrm{~Hz}$ ( SPL $=125 \mathrm{~dB}, A_{2}$ mode) and $7690 \mathrm{~Hz}$ ( $\mathrm{SPL}=137 \mathrm{~dB}, A_{1}$ mode) respectively. It is observed that these clearly stand out from the mixing and shockassociated noise, along with spikes at their first harmonics. The above two cases support the possibility that there could be two screech tone resonances occur at the same time or that screech-mode switching is present.

Figure 9 demonstrates the SPL for the case of $M_{j}=$ 1.10. This time, only a single distinct spike stands out in the spectrum. The spike corresponds to a screech frequency of $9040 \mathrm{~Hz}$ (SPL=1.39 dB, $A_{1}$ mode).

\subsection{Acoustics Properties Compared to Experiments}

Since the feedback loop is very sensitive to any change in the nozzle geometry, the computed screech tone fre- 


$$
P_{\text {maan }}=10144 \mathrm{kPa}
$$

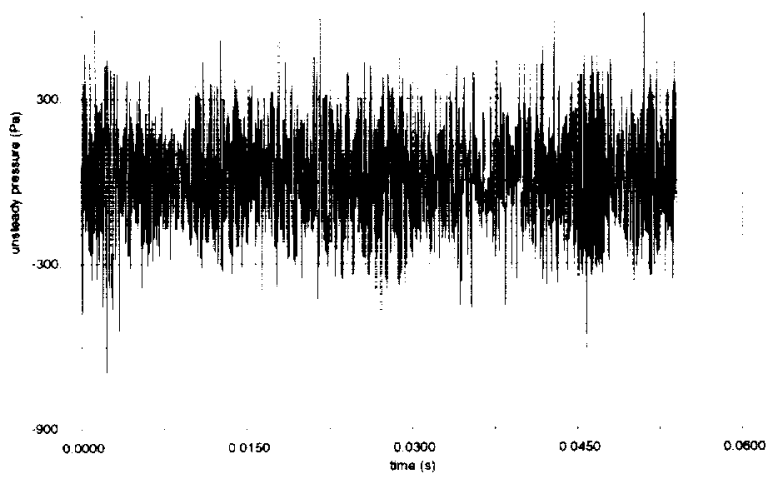

Figure 6: Time history of unsteady pressure at nozzle exit $(x=4.0, y=0.642), M_{j}=1.19$

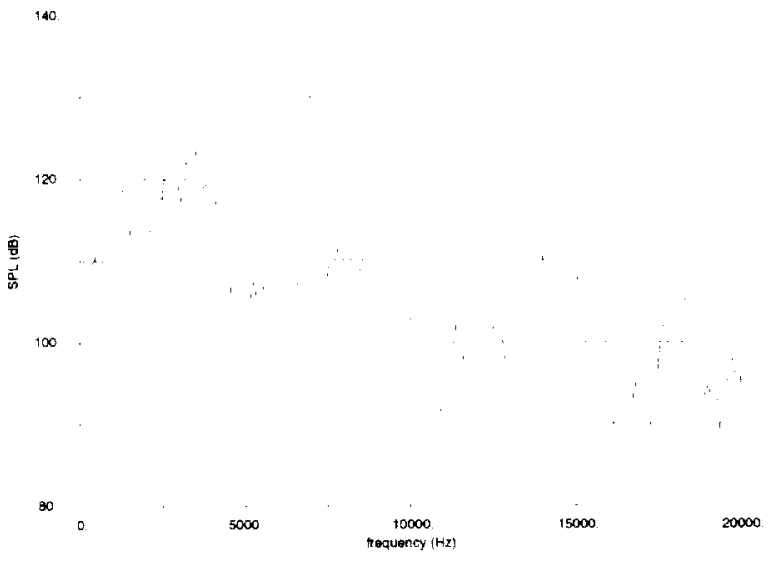

Figure 7: SPL at nozzle exit $(x=4.0, y=0.642), M_{j}=$ $1.19,75 \mathrm{~Hz}$ digital binwidth.

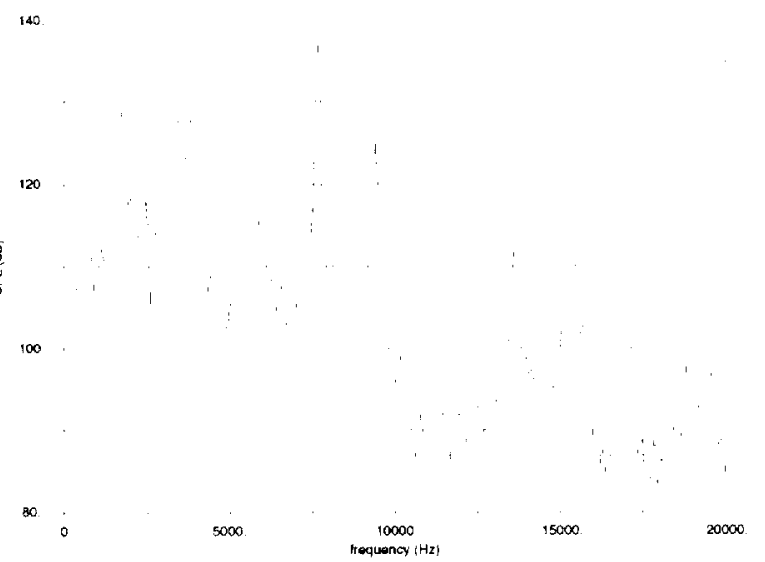

Figure 8: SPL at nozzle exit ( $x=4.0, y=0.642), M_{j}=$ $1.15,75 \mathrm{~Hz}$ digital binwidth.

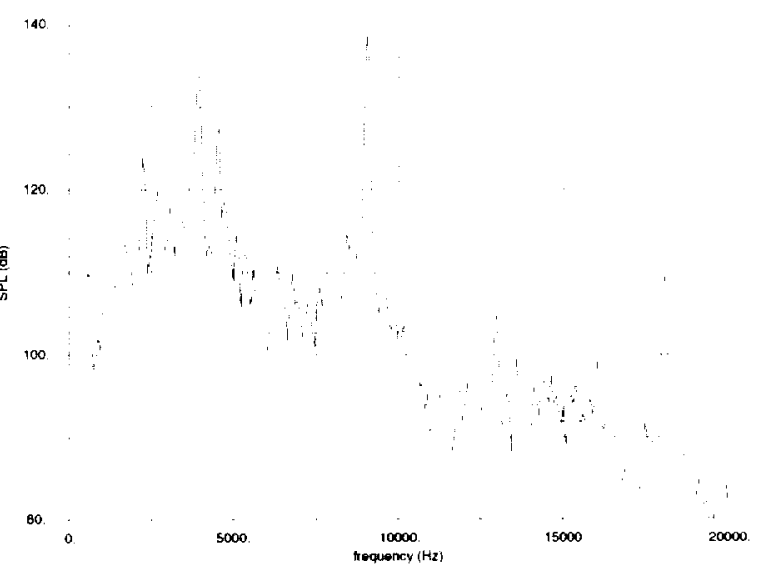

Figure 9: SPL at nozzle exit $(x=4.0, y=0.642), M_{j}=$ $1.10,75 \mathrm{~Hz}$ digital binwidth.

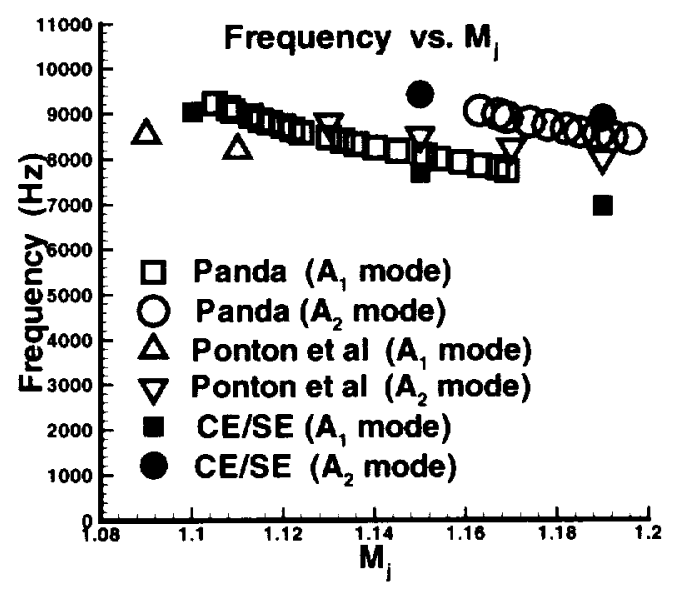

Figure 10: Comparison of screech tone frequencies .

quency and SPL are slightly different from those observed in experiments. Even between the experimental results of Panda et al. [7] and Ponton et al. [9], there are differences in the measured results due to general experimental setup and slight differences in nozzle lip thickness and shape, although they have the same nozzle diameters (25.4 mm) and operating Mach number.

The numerical results are summarized in Figs. 10 and 11 , and compared to the experimental data. Figure 10 displays a comparison of the screech tone frequencies between the numerical and experimental results. Both the experimental data of Panda et al. [7] and Ponton et al. [9] show distinctly the $A_{1}$ and $A_{2}$ screeching modes, and so does the numerical data. The CE/SE results agree reasonably well with Panda et al.'s [7] data and seem to have a consistent trends for the $A_{1}$ and $A_{2}$ modes. Their 


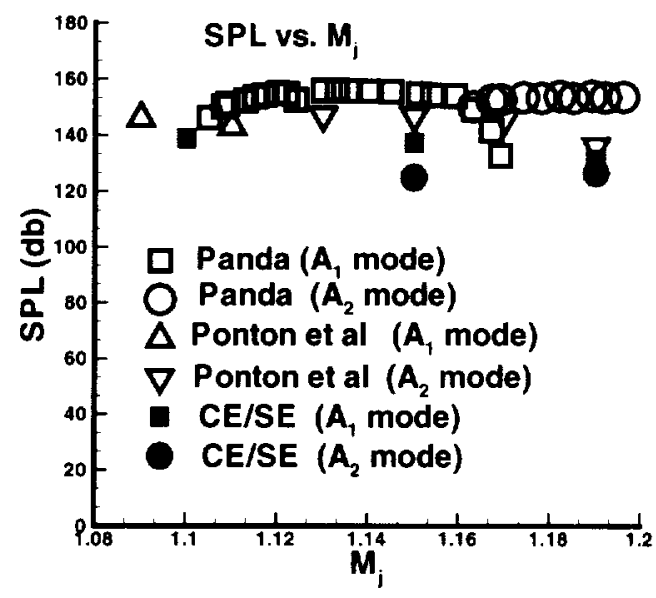

Figure 11: Comparison of screech tone SPL.

difference is less than the difference between the two experimental data sets of Panda et al. [7] and Ponton et al. [9]. Figure 11 demonstrates a comparison of the screech SPL between the numerical and experimental results. The computed SPL results are generally lower than the experimental ones, but-except for the $M_{j}=1.15$ case-are in general agreement with Ponton et al. s [9] data. It is not surprising that the numerical SPL agrees better with Ponton et al.'s [9] data, since their nozzle lip (thickness $=0.2 D$, no bevel) is used in the computation and the data is taken at the same location $y=0.642$ at the nozzle lip wall, while Panda et al.'s [7] data is taken at a slightly different location.

\section{Concluding Remarks}

In this paper, the unstructured CE/SE Navier-Stokes method is applied for screech tone noise analysis of an underexpanded supersonic axisymmetric jet.

Many hydrodynamic and acoustic aspects of the computed results are in good agreement with experimental findings [5-9], including the variation of screech frequency with mach number for the $A_{1}$ and $A_{2}$ modes. LES modeling was used to better capture the jet spreading but is not believed to be a critical element for the screech feedback loop.

The advantages of the CE/SE scheme were confirmed in the present simulation. The implementation did not require any special treatment or parameter selections to capture the acoustics. The simple yet robust CE/SE NRBC in combination with buffer zones virtually eliminates numerical reflections and allows for an effective near-field computation. The use of an unstructured grid offers flexibility to deal with more complicated geometries.

\section{References}

[1] Tam, C. K .W., "Supersonic Jet Noise," Ann. Rev. Fluid Mech. vol. 27, pp. 17-43 (1995).

[2] Seiner, J. M., "Advances in High Speed Jet Aeroacoustics," AIAA Paper 84-2275 (1984).

[3] Tam, C. K. W., "Jet Noise Generated by Large Scale Coherent Motion," NASA RP-1258, pp. 311-390 (1991).

[4] Raman G., "Advancees in Understanding Supersonic Jet Screech: Review and Perspective," Prog. Aerospace Sci. vol. 34, pp. 45-106 (1998).

[5] Panda, J., "Shock Oscillation in Underexpanded Screeching Jets," J. Fluid Mech., vol. 363, pp. 173198 (1998).

[6] Panda, J., "An Experimental Investigation of Screech Noise Generation," J. Fluid Mech., vol. 378, pp. 71-96 (1999).

[7] Panda, J., Raman, G. and Zaman, K. B. M. Q., “ Underexpanded Screeching Jets from Circular, Rectangular and Elliptic Nozzles", AIAA paper 97-1623 (1997).

[8] Panda, J, and Seasholtz, R.G, "Measurement of Shock Structure and Shock-Vortex Interaction in Underexpanded Jets Using Rayleigh Scattering", Phys. Fluids, vol. I1, pp. 3761-3777 (1999).

19) Ponton, M. K., Seiner, J. M. and Brown, M. C., “ Near Field Pressure Fluctuations in the Exit Plane of a Choked Axisymmetric Nozzle", NASA TM 113137 (1997).

[10] Shen, H. and Tam, C. K. W., "Numerical Simulation of the Generation of Axisymmetric Mode Jet Screech Tones," AIAA Paper 98-0283 (1998).

[11] Shen, H. and Tam, C. K. W., " Three-Dimensional Numerical Simulation of the Jet Screech Phenomenon" AIAA Paper 2001-0820 (2001).

[12] Chang, S. C., "The Method of Space-Time Conservation Element and Solution Element-A New Approach for Solving the Navier-Stokes and Euler Equations," Journal of Computational Physics. vol. 119, pp. 295-324 (1995). 
[13] Chang, S. C., Yu, S. T., Himansu, A., Wang, X. Y., Chow, C. Y. and Loh, C. Y., "The Method of Space-Time Conservation Element and Solution Element-A New Paradigm for Numerical Solution of Conservation Laws", Computational Fluid $D_{y}$ namics Review, eds. M. M. Hafez and K. Oshima, Wiley (1997).

[14] Chang, S.-C., Wang, X.-Y. and Chow, C.-Y., "The Space-Time Conservation Element and Solution Element Method-A New High Resolution and Genuinely Multidimensional Paradigm for Solving Conservation Laws," J. Comp. Phys. vol. 159, pp. 89-136 (1999).

[15] Wang, X.-Y. and Chang S.-C., " A 2-D Nonsplitting Unstructured Triangular Mesh Euler Solver Based on the Space-Time Conservation Element and Solution Element Method" C.F.D. J. vol. 8, pp309-325 (1999).

[16] Loh, C. Y., Hultgren, L. S. and Chang S.-C., "Computing Waves in Compressible Flow Using the Space-Time Conservation Element Solution Element Method," AIAA J., Vol. 39, pp. 794-801 (2001).

[17] Loh, C. Y., Hultgren, L. S., Chang, S.-C. and Jorgenson, P. C. E., "Vortex Dynamics Simulation in Aeroacoustics by the Space-Time Conservation Element Solution Element Method," AIAA Paper 990359 (1999).

[18] Loh, C. Y., Hultgren, L. S., Chang, S.-C. and Jorgenson, P. C. E., "Noise Computation of a Supersonic Shock-Containing Axisymmetric Jet by the CE/SE Method," AIAA Paper 2000-0475 (2000).

[19] Loh, C. Y., Chang, S.-C. and Scott, J. R., "Computational Aeroacoustics via the Space-Time Conservation Element/Solution Element Method", AIAA Paper 96-1687 (1996).

[20] Bogey, C., Bailly, C. and Juvé, D., "Computation of the Sound Radiated by a 3-D Jet Using Large Eddy Simulation," AIAA Paper 2000-2009 (2000). 
Public reporting burden for this collection af information is estimated to average 1 hour per response. including the tirne for reviewing instructions. searching existing data sources, gatherng and maintaining the data needed, and completing and reviewing the collection of intormation. Send comments regarding this burden estimale or any other aspect of this gatheng an inaing Davis Highway. Suite 1204. Arlington. VA 22202.4302, and to the Olfice ol Management and Budgel. Paperwork Re duction Project $10704-0188 \mathrm{p}$. Washington. DC 20503.

\begin{tabular}{|c|c|c|}
\hline 1. AGENCY USE ONLY (Leave blank) & $\begin{array}{l}\text { 2. REPOAT DATE } \\
\text { AlIgUSt 20()1 }\end{array}$ & $\begin{array}{l}\text { 3. REPORT TYPE AND DATES COVERED } \\
\text { Technical Memorandum }\end{array}$ \\
\hline
\end{tabular}

Near Field Screech Noise Computation for an Underexpanded

Supersonic Jet by the CE/SE Method

6. AUTHOR(S)

W( $-708-90-43-00$

Ching Y. Loh. Lennart S. Hultgren, and Philip C.E. Jorgenson

7. PERForming ORgANIZATION NAME(S) AND ADDRESS(ES)

National Aeronautics and Space Administralion

John H. Glenn Research Center at Lewis Field

Cleveland, Ohio 44135-3191

8. PERFORMING ORGANIZATION REPORT NUMBER

$\mathrm{E}-12813$

9. SPONSORING/MONITORING AGENCY NAME(S) AND ADDRESS(ES)

National Aeronautics and Space Administration

Washington, DC 20546-0001

SPONSORING/MONITORING AGENCY REPORT NUMBER

NASA TM-200]-210958

AlAA $-2001-2252$

11. SUPPLEMENTARY NOTES

Prepared for the Seventh Aeroacoustics Conference cosponsored by the American Insitute of Aeronautics and Astronautics and the Confederation of European Aerospace Societies, Maastricht. The Netherlands, May 28-30. 2001. Ching Y. Loh. Taitech. Inc.. 21000 Brookpark Road, Cleveland. Ohio 44135; Lennart S. Hultgren and Philip C.E. Jorgenson, NASA Glenn Research Center. Responsible person. Philip C.E. Jorgenson. organization code 5880. 216-433-5386.

12a. DISTRIBUTION/AVAILABILITY STATEMENT

12b. DISTAIBUTION CODE

Unclassified - Unlimited

Subject Categories: 01,71 and 45

Distribution: Nonstandard

Available electronically at hup://gltrs.grc.nasa.gov/(ILTRS

This publication is available from the NASA Center for AeroSpace Information. 301-621-1)390.

13. ABSTRACT (Maximum 200 words)

The space-time conservation element and solution element (CE/SE) method is employed to numerically study the near-field axisymmetric screech-tone noise of a typical underexpanded circular jet issuing from a sonic nozzle. For the computed cases, corresponding to fully expanded Mach numbers of $1.10,1.15$ and 1.19, the self-sustained feedback loop is automatically established. The computed shock-cell structure, acoustic wave length, screech tone frequencies, and sound pressure levels are in good agreement with experimental results.

\begin{tabular}{|c|c|c|c|}
\hline \multicolumn{3}{|c|}{$\begin{array}{l}\text { 14. SUBJECT TERMS } \\
\text { Screech noise: CE/SE method }\end{array}$} & $\begin{array}{l}\text { 15. NUMBER OF PAGES } \\
16 \\
\text { 16. PRICE CODE } \\
\text { 20. LIMITATION OF ABSTRACT }\end{array}$ \\
\hline
\end{tabular}


de 